\title{
Wittgenstein, McDowell y el reto escéptico ${ }^{1}$
}

\section{(Wittgenstein, McDowell and the skeptical challenge)}

\author{
María Teresa MuÑoz SÁNCHEZ
}

Recibido: 3 de diciembre de 2012

Aceptado: 21 de febrero de 2013

\section{Resumen}

En este artículo se defiende la siguiente tesis: Wittgenstein "exorciza" los argumentos escépticos mostrando una concepción alternativa del lenguaje y del conocimiento que ha dado en caracterizarse como naturalismo y quietismo. Y se ofrece un deslinde entre los planteamientos quietistas y naturalistas wittgensteinianos y el naturalismo propio del empirismo mínimo de McDowell. A diferencia de este último, la propuesta wittgensteiniana nos ofrece la posibilidad de rechazar el reto escéptico.

Palabras clave: naturalismo, quietismo, escepticismo, empirismo.

\begin{abstract}
In this article the following thesis is defended: Wittgenstein "exorcises" skeptical arguments by showing a conception of language and knowledge which has come to be characterized as naturalism and quietism. And this article distinguishes between Wittgensteinian quietist and naturalistic approaches, on the one hand, and McDowell's own naturalism, the minimal empiricism, on the other. Unlike the latter, the Wittgensteinian proposal offers us the possibility of rejecting the skeptical challenge.
\end{abstract}

Keywords: quietism, skepticism, empiricism and naturalism.

\footnotetext{
1 Agradezco especialmente los comentarios y sugerencias de los dictaminadores anónimos de esta revista.
} 
"El escepticismo no es irrebatible, sino manifiestamente absurdo, cuando quiere dudar allí donde no puede preguntarse".

(Wittgenstein TLP $\S 6.51$ )

"Lo difícil es encontrar el principio. O, mejor: es difícil comenzar desde el principio. Sin intentar retroceder más hacia atrás".

(Wittgenstein OC $\S 471$ )

1. De acuerdo con la concepción tradicional tripartita del conocimiento, un sujeto sabe algo, si y sólo si: el sujeto cree en ese algo (disposición psicológica), ese algo es verdadero (propiedad lógico-semántica) y el sujeto está justificado en creer ese algo (propiedad epistémica). De este modo, es una idea generalizada que el quehacer de la filosofía, con relación a esta concepción del conocimiento, radica en la justificación de las creencias. Dicha labor ha venido entendiéndose como una evaluación de la evidencia que se presenta para apoyar las creencias. El escepticismo cuestiona nuestra pretensión de conocimiento, y nos condiciona a proporcionar una justificación tal que elimine cualquier duda.

De la mano de Strawson, podemos caracterizar al escéptico no como "alguien que niega la validez de ciertos tipos de creencias, sino [como] alguien que cuestiona, aunque sea tan solo inicialmente y por motivos metodológicos, la pertinencia de las razones que tenemos para sostenerlas" (Strawson 1999, p. 43).

Si tenemos la convicción de que lo dicho por el escéptico no es posible, pareciera que estamos obligados a ofrecer un argumento con la fuerza suficiente como para derribar el suyo. La dificultad estriba en determinar en qué punto el argumento del escéptico presenta inconsistencias. La propuesta de Strawson al respecto es que tendemos de manera espontánea a pensar que todo lo sostenido por el escéptico es posible desde el punto de vista lógico, pero nos parece que no puede ser así. Sin embargo, para dar una respuesta satisfactoria al escepticismo es menester hacer a un lado nuestro rechazo inicial y demostrar cuando menos que, aun cuando el modo en el que el escéptico procede es válido para nuestras teorías tomadas aisladamente, no es concebible si se intenta hacer valer para todo aquello que creemos, considerado en conjunto ${ }^{2}$.

\footnotetext{
2 Strawson plantea que hay, hasta el momento, tres caminos para refutar el escepticismo: el primero, directamente, por medio del argumento racional, recurriendo al sentido común o a consideraciones teológicas o cuasi científicas; el segundo, de manera indirecta, mostrando que es de alguna forma ininteligible o contraproducente; y el tercero, es a través del naturalismo, cuyo representante, según Strawson es Hume, quien afirma que todos los argumentos a favor de la posición escéptica son totalmente ineficaces y, por el mismo motivo, que todos los argumentos contra dicha posición son totalmente inútiles. Strawson hace una analogía entre la posición humeana y la wittgensteiniana.
} 
2. Me propongo mostrar que la propuesta wittgensteiniana nos ofrece la posibilidad de rechazar el reto escéptico. De nuevo siguiendo a Strawson podemos afirmar que Wittgenstein no pretende una "justificación racional de la creencia en los objetos externos y otras mentes o de la práctica de la inducción, sino presentar los argumentos escépticos y los contrargumentos racionales como igualmente vanos -no carentes de sentido sino vanos-, puesto que lo que encontramos son compromisos ineludibles, naturales y originales que ni elegimos ni podríamos abandonar" (Strawson 1999, p. 75).

El recurso de Wittgenstein, no sólo para rechazar sino para "exorcizar" las conclusiones escépticas, es mostrar una concepción alternativa del lenguaje, que podemos encontrar en las Investigaciones Filosóficas, y una mirada al conocimiento que ubicamos en su obra póstuma Sobre la Certeza. En estas obras, Wittgenstein prescinde de la dualidad lenguaje/mundo, sujeto/objeto o acción/contemplación como marcos para estructurar por separado cada uno de los elementos de estas duplas. Así, no establece dos ámbitos de reflexión, el relativo al mundo y el relacionado con el lenguaje, sino que centra su atención en el lenguaje, para descentrar desde él al mundo. De manera que es posible afirmar, siguiendo esta lectura, que nuestro conocimiento del mundo se articula lingüísticamente y en interna relación con el ámbito de unas prácticas socialmente compartidas. Dichas prácticas regulan el significado de nuestros conceptos. A esta manera de explicar el conocimiento y la relación entre lenguaje y mundo la denomino naturalismo social ${ }^{3}$. Pues bien, desde esta apropiación del pensamiento wittgensteiniano podemos revisar el reto escéptico y superarlo.

3. Es ya un lugar común en la filosofía contemporánea la afirmación de que el naturalismo tiene diferentes significados para diferentes personas (De Cairo and Macarthur (comp) 2004, p. 3). No será éste el lugar para esclarecer los parecidos de familia entre las distintas versiones del naturalismo. Sin embargo, sí he de ocuparme, aunque sea de manera breve, de una relación aparentemente conflictiva; a saber, la que puede establecerse entre naturalismo y quietismo. Esta es una relación indudablemente fructífera, como se verá. Me parece interesante deslindar los planteamientos quietistas y naturalistas wittgensteinianos de cierta forma de naturalismo que, desde mi análisis, no nos ayudaría a responder adecuadamente al reto escéptico. Se trata del empirismo mínimo de McDowell. Empezaré por ahí.

\footnotetext{
3 También José Medina (2004) caracteriza el planteamiento de Wittgenstein como naturalismo social. En su argumentación se centra en Remarks on the Philosophy of Psychology.
} 


\section{El empirismo mínimo de J. McDowell}

1. En su influyente obra Mind and World (1994), McDowell pretende "curar" algunas de las ansiedades filosóficas características de la Modernidad, en especial las relativas a la relación mente mundo. Dichas ansiedades pueden englobarse en tres grandes dicotomías: Naturaleza-Razón, Fundacionismo-Coherentismo y Realismo-Idealismo. Tal como afirma en la introducción, McDowell pretende rastrear el origen de dichas angustias filosóficas a las que considera mera ilusión. El método al que recurre no consiste en responder a las preguntas planteadas por la Modernidad, pero tampoco en abandonar el proyecto. Nos propone una caracterización mínima del empirismo de acuerdo con la cual la experiencia desempeña el papel de "tribunal" que juzga y determina la corrección de nuestros juicios y creencias. "Un buen camino para penetrar en la imagen que ofrezco es el de considera la plausibilidad de un empirismo mínimo -no dice-".

La experiencia, parecer sugerirnos McDowell, puede proveernos razones para justificar algunas de nuestras creencias; por lo menos, diríamos, aquellas creencias que son acerca del mundo. ¿Cómo puede la experiencia servir para justificar creencias sin caer en la ansiedad del fundacionismo? Consideraré aquí la respuesta de McDowell a esta cuestión. La reconstruiré como un intento de salvar una intuición realista, a saber: para que el pensamiento empírico sea genuinamente pensamiento acerca del mundo, la experiencia debe servir para justificar nuestras creencias acerca del mundo. Desde mi punto de vista, pese a McDowell, esta propuesta tiene como trasfondo dar razón de la posibilidad del conocimiento empírico, esto es, en algún sentido, responder al reto escéptico.

2. Para McDowell, la experiencia -el mundo-debe ser el juez que determina la corrección de nuestro pensamiento - creencias y juicios-. De ahí que considere como requisito indispensable para el empirismo mínimo que el mundo ejerza un control racional externo a las creencias; es decir, las creencias y juicios están estructurados de tal manera que son "responsables ante el mundo" (answerable to the world):

Lo que quiero dar a entender con la expresión "empirismo mínimo" -nos dice McDowell-es justamente esto: la idea de que la experiencia debe constituirse como un tribunal que media en el modo en que nuestro pensamiento es responsable ante cómo son las cosas, si es que queremos entender tal pensamiento como pensamiento. (McDowell 1994, xiii) (la traducción es mía)

De modo que la normatividad que rige nuestro conocimiento es entendida en términos de la responsabilidad de nuestras creencias hacia el mundo -hacia cómo son las cosas realmente-, en tanto que es éste el que determina su corrección. McDowell afirma que al caracterizar a un episodio como conocimiento es necesario "tener al mundo a la vista". 
A diferencia de autores como Davidson, Rorty, Brandom y Sellars, que nos proponen abandonar el empirismo ${ }^{4}$, McDowell nos insta a recuperarlo. Piensa que en él opera una intuición realista legítima que no puede ser rechazada; dicha intuición es que el mundo debe entenderse como constreñimiento externo al pensamiento. Este énfasis en el empirismo le lleva a ocuparse con mucho detenimiento de una de las dificultades con la que se topan las teorías epistemológicas de corte empirista, a saber: la llamada falacia naturalista. Esto es, la acusación de que no distinguen entre la descripción empírica del proceso de adquisición del conocimiento y el marco normativo de justificación de las creencias. Así, nos ofrece una caracterización de la experiencia que pretende "exorcizar" este problema respetando la "legítima intuición realista" de que necesitamos mantener contacto con el mundo en términos normativos, esto es, la idea de que los juicios y las creencias tienen responsabilidad hacia el mundo.

Veamos, muy rápida y esquemáticamente, las posibilidades de solución ofrecidas por McDowell. La primera es mediante la renuncia a la concepción de experiencia como conjunto de impresiones. La idea de experiencia que recupera es una concepción de espíritu kantiano (McDowell 1994, p. 94), según la cual, ésta es entendida como conceptualmente estructurada. Asumir esto implica que incluso la experiencia sensorial posee contenido conceptual. La experiencia se da por la interacción de receptividad y espontaneidad; es por ello que posee contenido conceptual. Pero, ¿cómo podemos hacer relevantes las experiencias perceptuales para la justificación de nuestras creencias empíricas? Para McDowell, esta pregunta no es más que una cuestión subsidiaria de una ansiedad trascendental de carácter general que rodea al empirismo: ¿cómo es posible que nuestro pensamiento sea acerca de una realidad objetiva, externa a él? Es decir, ¿cómo es posible el contenido empírico? Esta pregunta se sostiene en dos supuestos, que son precisamente los que vuelven la cuestión una ansiedad filosófica: en primer lugar, el supuesto según el cual para que el pensamiento pueda ser acerca del mundo externo, debe haber relaciones racionales de justificación entre la experiencia perceptual y las creencias empíricas. En segundo lugar, el supuesto de que las impresiones de sensación de la sensibilidad son un fenómeno natural, externo al espacio lógico de las razones. Es este segundo supuesto el que, de acuerdo con McDowell, produce la sensación de que la experiencia perceptual no puede jugar ningún papel relevante en el plano de la justificación. Y es que las justificaciones ocurren solamente dentro del espacio lógico de las razones; pretender justificar una creencia acudiendo a la experiencia sería pretender salirse de este espacio, lo cual significaría caer en el Mito de lo Dado. McDowell rechaza este supuesto.

\footnotetext{
${ }^{4}$ Los autores antes citados que rechazan el empirismo lo hacen sobre la base de que no es posible considerar a la experiencia como epistémicamente relevante, debido a que su función es ser fuente causal del conocimiento empírico.
} 
Así, la segunda solución a la falacia naturalista es mostrar que las experiencias no son ajenas al espacio de las razones. La experiencia es, por el contrario, una actualización de capacidades conceptuales, capacidades cuya actualización y ejercicio es parte del espacio lógico de las razones. La recepción de impresiones es para McDowell un fenómeno perteneciente a una segunda naturaleza. Las capacidades conceptuales relevantes para poder ofrecer razones a favor o en contra de una creencia son posibilitadas con la adquisición de un lenguaje. Y adquirir un lenguaje es adquirir una segunda naturaleza. Por lo tanto, la experiencia, que actualiza tales capacidades, es un fenómeno también perteneciente a esta segunda naturaleza.

Pero McDowell acepta el primer supuesto. Es un hecho, para él, que si queremos decir que nuestro pensamiento y nuestros juicios son acerca de una realidad independiente de ellos, necesitamos alguna clase de constricción racional externa a ellos; esta constricción la cumple la experiencia perceptual, que juega un rol normativo respecto del conocimiento empírico. Este supuesto es, sin embargo, el mismo que da pie al Mito de lo Dado.

2. La pregunta relevante ahora es si con esta propuesta ha planteado una noción de experiencia que nos permita eludir o superar el reto escéptico ${ }^{5}$. Considero que la manifiesta preocupación de McDowell por la experiencia le lleva a establecer un modelo que privilegia los enunciados observacionales sobre los teóricos. Pareciera que dichos enunciados resultan transparentes y están directamente sujetos al tribunal de la experiencia. A fin de constatar esta interpretación, no tenemos más que releer la siguiente cita:

Para darle sentido a la idea de que un estado o un episodio mental están dirigidos hacia el mundo, a la manera en que, digamos, una creencia o un juicio lo están, necesitamos poner ese estado o ese episodio en un contexto normativo. Una creencia o un juicio de que las cosas son de tal y cual modo (una creencia o un juicio cuyo contenido -como se suele decir-es que las cosas son de tal y cual modo) debe ser una actitud o postura que se adopta correcta o incorrectamente en función de si las cosas son efectivamente de tal y cual modo. (...) Tal relación entre la mente y el mundo es normativa, por tanto, en este sentido: en que el pensamiento que se dirige hacia un juicio o hacia la fijación de una creencia se hace responsable ante el mundo -ante cómo son las cosas- de si resulta o no correcto. (McDowell 1994, xi-xii)

\footnotetext{
5 Rojas Parada ofrece una interesante reflexión acerca de la experiencia en la propuesta de McDowell: "Parecería que a la experiencia, concebida según el modelo de McDowell, le pasa lo mismo que sucede al jugar a las Siete y media: o no llegas o te pasas. Para escapar del coherentismo, McDowell precisa que la experiencia no sea todavía una creencia. Por tanto, necesita que esté vacía de compromiso dóxico. Pero entonces no vemos cómo se puede eventualmente transmutar esa actitud dóxicamente neutral en otra que sí comporte un elemento de convicción. Nos hemos quedado cortos. Pero si dotamos a la invitación experiencial de una dosis siquiera mínima de aceptación, introduciéndola en el contexto más amplio de una visión del mundo ya asumida y vigente, entonces nos pasamos y caemos del lado del coherentismo. Cabría pensar, pues, bastante razonablemente, que la experiencia mcdowelliana no puede finalmente satisfacer los objetivos" (Rojas 2009, p. 188).
} 
Sin embargo, como nos recuerda Rorty, "En materia de arte, moral y política queremos juzgar correctamente, pero hablar de "dirección hacia el mundo" y de cosas que "efectivamente [son] de tal y tal manera" suena hueco." (Rorty 2000, p. 184) Además, aunque la experiencia es presenta por McDowell como conceptualmente determinada, sigue mostrándose como espacio privilegiado, individual y privado desde el cual determinar la validez del conocimiento. El recurso a la experiencia pensada en los términos antes dichos - es decir, como privilegiada, individual y privada-nos conduce sin remedio al escepticismo, como mostró Davidson de manera atinada: "Si nuestro conocimiento del mundo deriva enteramente de evidencias de este tipo, [es decir, de evidencias empíricas] entonces no sólo nuestros sentidos pueden engañarnos a veces; es posible que estemos general y sistemáticamente engañados." (Davidson 1983, p. 44) De acuerdo con Davidson, cómo percibe cada sujeto las cosas, qué imágenes ve, qué sonidos escucha, todo ese abigarrado y complejo mundo de las percepciones es un mundo privado, irrelevante cuando nos interrogamos por la estructura de nuestro conocimiento y de la realidad. También Wittgenstein muestra atinadamente que las sensaciones privadas no desempeñan ningún papel en nuestros juegos de lenguaje; la otra persona y yo coordinaremos nuestras acciones, juicios y creencias sin ningún problema, porque lo relevante no es la imagen que se forma en mis ojos, de la que sólo yo soy consciente, sino la dimensión pública de nuestras acciones y palabras. Éstas esquivan el factor subjetivo experiencial y se corresponden directamente con el mundo. El empirismo mínimo de McDowell, con su énfasis en la experiencia, adopta una perspectiva individualista que, tal como Brandom le criticó en su momento, "minimiza sistemáticamente la significación de la dimensión social de la práctica de dar y pedir razones" (Brandom 1995a, p. 256) (Cfr. Brandom 1995b, p. 904).

4. Con su planteamiento "terapéutico", McDowell pretende ubicarse entre los filósofos quietistas de raigambre wittgensteiniana. Eso sí, toma distancia de la estrategia de Rorty, como sabemos otro terapeuta confeso wittgensteinano, quien sí abandona el tradicional proyecto epistemológico de la Modernidad. McDowell, en otro tenor, pretende "exorcizarlo", es decir, según su propia percepción, pretende haber arrancado de raíz todos los falsos dilemas propios de la Modernidad pero nos ofrece una propuesta constructiva. En este sentido, si bien McDowell insiste en que su actitud es la de curar ciertas ilusiones de la Modernidad, lo cierto es que su anhelo de respetar la "legitima" inquietud realista acerca de la conexión entre el mundo y nuestros pensamientos, lo lleva a ofrecer un nuevo modelo de realismo epistemológico -"la doctrina según la cual el conocimiento humano del mundo externo constituye un objeto de ponderación apropiado"(Rorty 2000, p. 206) -. La cuestión entonces es si este modelo no deja a McDowell a expensas del escepticismo. Desde mi lectura, así es. 


\section{La terapia wittgensteiniana}

La certeza es, por decirlo así, un tono en el que se constata cómo son las cosas; pero del tono no se sigue que uno esté justificado.

$(\mathrm{OC} \S 29)$

1. Frente a la mirada de McDowell, quien enfrentaría al escéptico proponiendo una nueva versión del empirismo que eludiría la acusación de caer en el Mito de lo Dado, Wittgenstein nos ofrece una forma de naturalismo, según la cual sólo apelando a las formas de vida dadas y a las prácticas que en ellas se desarrollan es posible plantearse preguntas acerca del conocimiento, la creencia o la verdad. Ninguna justificación de la validez del conocimiento y el lenguaje puede basarse en una relación privilegiada con la realidad. A partir de la lectura de Wittgenstein es posible repensar una concepción de la normatividad epistémica y la justificación lingüística que recupera la relevancia de las prácticas sociales y el carácter social del lenguaje, tanto en los procesos de justificación de creencias como para dar razón de lo que hace significativo el uso de los términos. De esta forma, es posible recuperar el nexo entre significado y normatividad atendiendo al carácter histórico social del lenguaje.

En el apartado previo, hemos visto un modelo neo-empirista de justificación del conocimiento que roza el fundacionismo. Me propongo ahora mostrar la propuesta wittgensteiniana de explicación del lenguaje en la que se vincula la normatividad y el significado sin apelar a criterios empiristas. Concluiré mostrando las virtudes de este modelo de normatividad frente a la concepción del empirismo mínimo.

2. Para defender esta lectura me detendré especialmente, aunque no solo, en su obra póstuma, On Certainty. No es mi interés en este artículo entrar en el debate acerca del llamado 'tercer Wittgenstein', esto es, sobre si esta última obra constituye o no una nueva y tercera etapa en su pensamiento. Coincido con R. Rhees (2003, p. 5) en que el tratamiento de los temas considerados en On Certainty no comienza 1949. Por supuesto, esto no impide que concuerde con Malcolm en que

Los últimos cuadernos de Wittgenstein, publicados bajo el título Sobre la Certeza, fueron escritos en el último año y medio de su vida. Son notas toscas, totalmente sin revisar. Son sus discusiones consigo mismo, sin previsión alguna de publicación. ... Muchos lectores encuentran todo ello desconcertante. Pero estas notas recompensan el estudio duro. No sólo hay observaciones individuales de gran belleza, también emergen líneas de pensamiento que no se encuentran en otras partes en los escritos de Wittgenstein. (Malcolm 1986, p. 201)

Efectivamente en este escrito, Wittgenstein afronta conceptos y problemas desde una perspectiva novedosa. Me refiero aquí precisamente a los términos epis- 
temológicos tales como duda, creencia y conocimiento. Tal acercamiento no es, por cierto, ajeno a determinados planteamientos previos expresados fundamentalmente en las Investigaciones Filosóficas ${ }^{6}$ e incluso puede vincularse con el Tractatus ${ }^{7}$.

Sin duda, On Certainty es un texto estimulante en diversos sentidos, sin embargo, me centraré aquí en los aspectos relacionados con él que me parecen relevantes para el tema que me ocupa en este artículo, el escepticismo. El primer asunto que rescato es su concepción de las criptoproposiciones (Strawson) o proposiciones bisagra (Moyal-Sharrock), que considero fundamental para entender el rechazo al reto escéptico. El segundo punto es la discusión desatada acerca del presunto y novedoso fundacionismo wittgensteiniano. Así, dedicaré gran parte de esta segunda sección del artículo a tomar distancia de las interpretaciones fundacionalistas acerca de On Certainty. La manera wittgensteiniana de tratar al escepticismo en esta obra, así como en las Investigaciones Filosóficas, no nos permite caracterizar su propuesta como un nuevo fundacionismo (Cfr. Avrum Stroll 1994 y 2005), (Cfr. Moyal-Sharrock 2004a y 2004b, 2005).

3. Para comenzar el análisis de On Certainty, partiré de las que Strawson denomina criptoproposiciones. Son proposiciones que aceptamos sin cuestionarnos, que de hecho asumimos al ser introducidos en una forma de vida (OC §94) y en los juegos de lenguaje que ella conlleva (OC §170). Estas proposiciones constituyen reglas que permiten justificar otras proposiciones no exentas de duda. Nuestros lenguajes están compuestos de observaciones, las cuales, bajo la apariencia de constataciones -tales como "Hay objetos", "Los objetos no desaparecen"'-, muestran criterios de uso de los términos. Este carácter normativo es lo que hace de ellas reglas del lenguaje. Es preciso señalar que no todas las proposiciones tienen este peculiar papel normativo - aunque, dependiendo del contexto, puedan tenerlo- (OC §83). En determinados contextos una proposición empírica puede convertirse en -jugar el rol de-indubitable, (OC §167, 318-321 y 371) y así pasar a ser una observación o regla gramatical.

Puede suceder, por ejemplo, que toda nuestra investigación se establezca de tal modo que ciertas proposiciones, una vez formuladas, queden al margen de la duda. Permanecen en los márgenes del camino que recorre la investigación (Wittgenstein OC $\S 88)$.

\footnotetext{
6 Son muchos los autores que han defendido la tesis de la continuidad. Menciono aquí a José Molina (2004) por compartir con él su interpretación naturalista. Molina encuentra continuidad en los planteamientos de Wittgenstein no sólo entre las Philosophical Investigations y On Certainty sino también con el Tractatus.

7 Puede consultarse un artículo muy revelador de Stella Villarmea (2010), donde establece una comparación entre los diferentes usos de los conceptos epistémicos que Wittgenstein desarrolla en $O n$ Certainty, y su distinción entre lo que tiene significación (meaningful), lo que no tiene sentido (senseless) y lo que es absurdo (nonsense) en el Tractatus.
} 
El que esto ocurra no depende, en sentido estricto, del contenido de la proposición, esto es, de la creencia que expresa ni del hablante, sino del contexto y de la acción lingüística. Son, entonces, los juegos del lenguaje y las formas de vida los que articulan éstas, y no otras, como proposiciones exentas de duda (OC §161). Para el asunto que ahora nos ocupa, aprendemos a confiar en la indubitabilidad de ciertas proposiciones tales como "Hay objetos", "Los objetos no desaparecen" "Mi cuerpo no desaparece". Y éstas adquieren o mantienen dentro de ciertos juegos de lenguaje un estatuto diferente: lo relevante no es su contenido informativo sino que determinan los márgenes del sentido de ciertos juegos de lenguaje en el contexto de una forma de vida. Se trata de creencias cuyo valor epistémico no se debe a su relación con la experiencia o el mundo (OC §130-131). Su valor, su rol, es asunto que, en última instancia, sólo puede decidirse a partir de nuestro tráfico con la realidad, a partir de nuestras prácticas, de nuestros juegos de lenguaje y de nuestras formas de vida. No es desde una realidad pre-gramatical que, a la manera de fundamento, sostenemos dichas proposiciones. Estas proposiciones no requieren de fundamento.

Se me podría cuestionar acerca de si la afirmación de que hay proposiciones exentas de duda, proposiciones que, como acabo de señalar, no requieren de fundamento, no responde a una concepción fundacional. Lo que es más, ¿qué es lo que fija el valor normativo de dichas proposiciones?, ¿qué relación guardan con el resto de nuestras creencias? Estas mismas preguntas son las que, tratan de responder Stroll $(1994,2004$ y 2005) y Moyal-Sharrok $(2004,2005)$ con sus planteamientos. Y su respuesta, dicha muy precipitadamente, es que constituyen un tipo especial y novedoso de fundamento para el resto de las proposiciones. Desde mi punto de vista, la respuesta a estas preguntas sería que estas creencias conforman nuestro marco de referencia (OC §83). Estas certezas adquieren su estatuto por la relación establecida entre formas de vida y juegos de lenguaje. Al mismo tiempo, son estas proposiciones las que estructuran nuestros juegos de lenguaje.

De manera que no pueden ser entendidas a la manera de experiencias pre-lingüísticas que sirva de evidencia epistémica o de soporte para el resto del conocimiento. Son prácticas sociales lo que encontramos detrás de nuestras actitudes epistémicas: lo verdaderamente primario son las prácticas sociales en las que somos introducidos al aprender un lenguaje, al compartir una forma de vida (OC §95). Recordemos con Wittgenstein: "El niño aprende al creer al adulto. La duda viene después de la creencia." (OC §160). Estas afirmaciones no me comprometen con la tesis de que en On Certainty encontramos un cierto fundacionalismo ni tradicional ni de nuevo cuño. A continuación argumentaré al respecto.

4. Una precisión es necesaria llegados a este punto: por fundacionismo entiendo una concepción del conocimiento y de la justificación según la cual todo conocimiento o creencia justificada descansa en una creencia no inferencial indubitable. Sobre esta base se establece el resto del conocimiento. Así, el conocimiento, desde 
esta perspectiva, se concibe con una cierta estructura, a saber: las proposiciones que justifican están en la base.

De manera que, las respuestas ofrecidas al reto escéptico desde una posición fundacionista han buscado legitimar la existencia de dichas creencias o proposiciones fundamentales que están a la base. Tal es el caso emblemático de Descartes, de cuyo fundacionismo Stroll distancia el nuevo fundacionismo wittgensteiniano (2004, p. 15). Pero también es el caso de las teorías de los sense data. Las epistemologías de corte fundacionista buscan explicar el resto del conocimiento como cimentado en esta base mínima. Las proposiciones que constituyen el resto del conocimiento y cuya justificación depende de un proceso de inferencia, tienen su apoyo último en estas otras proposiciones que no son fruto de un proceso inferencial. Es esta noción de fundacionismo, contra la que Sellars argumentó en Empiricism and The Philosophy of Mind (1997), el que me interesa discutir aquí y del que, en primera instancia, me interesa deslindar a Wittgenstein. Al mismo tiempo, mostraré que tampoco es posible ubicarle en otro tipo novedoso de fundacionismo so pena de desdibujar las características propias del fundacionismo.

5. En su conocido texto Moore and Wittgenstein on Certainty, Avrum Stroll enfatiza que en esta última obra de Wittgenstein aparece de manera novedosa la idea de que los juegos de lenguaje descansan en un fundamento. ${ }^{8}$ Según su interpretación, en esta última obra, Wittgenstein coloca los fundamentos de los juegos de lenguaje fuera de los mismos, pero como sostén de ellos (1994, p. 138). En este punto, Stroll apela a una distinción entre formas relativas y absolutas de certeza. Las primeras se refieren a proposiciones que pueden ponerse en duda en ciertos contextos y no en otros. Las certezas absolutas son aquellas que no tendría sentido dudar en ningún contexto. Son estas últimas las que constituyen un soporte, un fundamento para los juegos de lenguaje; un fundamento para el conocimiento. De este modo, nos encontraríamos ante un fundacionismo que permite establecer una base para el resto del conocimiento y distinguir entre aquellas creencias que se sostienen en inferencias previas y aquellas que no requieren justificación. Ahora bien, el fundacionismo de Wittgenstein presentaría, de acuerdo con esta lectura, rasgos que le distancian de lo que Stroll denomina fundacionismo homogéneo. Se trata de un tipo de fundacionismo no homogéneo que caracteriza del siguiente modo:

La genialidad de Wittgenstein consistió en construir una explicación del conocimiento humano cuyos cimientos, cuyos presupuestos de apoyo, no eran de ninguna manera como el conocimiento. El conocimiento pertenece al juego de lenguaje, y la certidumbre no. La base y la mansión que descansa en ella son completamente diferentes (Stroll 1994: 145 [todas las traducciones son mías]).

\footnotetext{
8 Esta concepción, ausente en las Investigaciones Filosóficas, justificará más tarde (2004) el apoyo de Stroll a la denominación de Tercer Wittgenstein propuesta por Moyal-Sharrock (2004a) para las notas que fueron publicadas tras el fallecimiento de Wittgenstein y tituladas On Certainty.
} 
En "Wittgensten's Foundational Metaphors", además de recurrir a la idea de que el lenguaje metafórico usado por Wittgenstein en On Certainty tiene como objetivo ayudar al lector a visualizar este presunto fundacionismo, nos dice:

Esta es una forma peculiar de fundacionismo que no es doxástica ni no-doxástica en el sentido en el que los filósofos utilizan convencionalmente esos términos. Tiene características tanto no tradicionales como tradicionales. En éste último sentido, sostiene que lo que es fundamento difiere radicalmente en carácter del edificio que soporta (Stroll 2004, p. 13).

La genialidad de Wittgenstein habría consistido en encontrar en las certezas no proposicionales una base que soporte el edificio del conocimiento. Ciertamente, Stroll se lamenta de que Wittgenstein vacila entre una descripción proposicional o no-proposicional, de lo que constituye el fundamento. De acuerdo con su explicación los primeros parágrafos de On Certainty están dedicados a criticar la propuesta de Moore y en ellos se centra en una concepción proposicional de la certeza. Son los últimos parágrafos de la obra los que le permiten defender que nuestras prácticas con relación al conocimiento se sostienen sobre un fundamento no proposicional. Precisamente por este carácter no proposicional, alega Stroll, Wittgenstein recurre a distintas metáforas que nos proporcionan una imagen, "nos inducen a entender que las nociones de verdad, justificación, evidencia, prueba y demás no son aplicables a lo que subyace al juego de lenguaje" (2004, p. 21). Se trata de metáforas tales como el lecho del río (OC §96), los ejes sobre los cuales todo gira (OC $\S 152)$, el fundamento que sostiene el edificio (OC §248). De manera que, según esta lectura, lo que sostiene el edificio del conocimiento tiene un carácter radicalmente diferente del edificio que sostiene. Así señala "varios candidatos para $\mathrm{F}$ [lo que es absolutamente fundacional en nuestro lenguaje], y todos ellos no intelectuales. Entre estos están actuar, ser entrenado en prácticas comunes, instinto y demás" (Stroll 1994, p. 146) En su afán de enfatizar el carácter no proposicional de las proposiciones bisagra señala que

(...) las proposiciones bisagra no son proposiciones en ningún sentido tradicional del término y, en particular, no son mentales - un "tipo de ver, por decirlo así". Tampoco son claramente empíricas -aunque parezcan serlo. Incluso la idea de que son "reglas gramaticales" fue vista como una sobre-intelectualización de lo que él [Wittgenstein] estaba tratando de hacer. En cambio, [Wittgenstein] comenzó a concebir la certeza como un modo de actuar. La idea de que la acción se encuentra en el fondo del juego de lenguaje (en lugar de cualquier sistema de proposiciones) es una concepción nueva y radical de la certeza. La certeza proviene de la inmersión en una comunidad humana en la que entrenamiento rutinario y la inculcación de hábitos crean el sustrato sobre el cual descansa el juego del lenguaje. Esta concepción no proposicional de la certidumbre separa radicalmente a Wittgenstein de la tradición. (Stroll 1994, p. 155) 
Tres son las objeciones que tengo a este planteamiento: la primera es que pese a esta distancia del modelo tradicional, en la lectura de Stroll sigue apareciendo la idea del conocimiento como un edificio que es soportado por, en el caso wittgensteiniano, algo externo al edificio mismo. La idea propia del fundacionismo acerca de una base sobre la cual construir el conocimiento se sostiene. Efectivamente este sería uno de los rasgos que permitiría hablar de un fundacionismo en Wittgenstein; un fundacionismo en el sentido tradicional. Sin embargo, el rol de las proposiciones bisagra, o las criptoproposiciones en terminología de Strawson, no es ser base, sino marco de referencia, sobre este punto abundaré más abajo. Mi segunda objeción es su identificación del fundamento con lo non-intelectual. Cuando Stroll enfatiza la no-proposicionalidad de las proposiciones bisagra revisa los siguientes apartados (OC $\S 204,253,358,359,475)$. Pareciera entonces que Stroll vincula, especialmente en los tres primeros parágrafos referidos, las proposiciones bisagra con nuestro actuar, con lo dado, con las formas de vida. Pero tanto en On Certainty como en Philosophical Investigations, Wittgenstein presenta las formas de vida como lo dado, aquello que sirve de estructura o marco a nuestros juegos de lenguaje y que se nutre también con los diversos juegos de lenguaje. Las formas de vida no son únicamente las formas instintivas de actuar a las que Stroll alude recuperando los parágrafos de On Certainty 359 y 475 . El uso de la expresión 'forma de vida' es equívoco en Wittgenstein, oscila entre: a) 'forma de vida' como el dato de nuestra 'historia natural', como la forma de vida de los humanos, y b) 'forma de vida' como el conjunto de costumbres, hábitos, normas e instituciones. Si atendemos a esta segunda acepción, como lo dado en tanto que actividad socializada, institucionalizada y caracterizada por el uso o la aplicación de términos, y no meramente como dato de nuestra historia natural no podemos pensar que lo que "fundamenta" nuestro conocimiento, - si es que algo fundamenta-, es únicamente lo que tiene carácter de no-intelectual. Por último, mi tercera objeción es que la propuesta de lectura de Stroll muestra un Wittgenstein deseoso de dar respuesta al escéptico a través de la construcción de una teoría alternativa. Esto alejaría a Wittgenstein de unos de sus rasgos más relevantes, su anhelo de hacer filosofía describiendo el uso de nuestro lenguaje y no construyendo sistemas. Si aceptamos la lectura de Stroll, esta última obra de Wittgenstein se alejaría de carácter terapéutico que ha caracterizado sus trabajos y supondría la defensa más o menos implícita -o metafórica (Stroll 2004)- de las tesis básicas del fundacionismo. Wittgenstein habría elaborado una teoría del conocimiento alternativa. La pretensión de Wittgenstein no es explicar el lenguaje sino describir los usos de los términos (IP 109). La estrategia interpretativa de Stroll le conduce a la defensa una sublimación de la pregunta filosófica, en lugar de mostrar su propuesta como un desmantelamiento de la investigación filosófica (Cardona 2011). Por las razones que se expondrán en el último apartado de este texto, "Naturalismo y quietismo", creo que ésta es una lectura errada de $O n$ Certainty. 
6. En la misma línea de interpretación que Stroll se encuentra el planeamiento de Moyal-Scharrock (2005). Para defender una lectura fundacionista del que denomina "Tercer Wittgenstein", ella distingue entre certidumbres objetivas y certezas objetivas. Estas últimas son consideradas fundacionales en dos sentidos: en tanto categoría doxástica, por un lado, y en tanto actitud doxástica, por otro. Las certezas objetivas, entendidas como categorías doxásticas, son aquellas creencias dentro de nuestro(s) sistema(s) de creencias, que "actúan como reglas de gramática". Ejemplos de ella los encontramos en los parágrafos de On Certainty en los que Wittgenstein habla de que con ciertas proposiciones, "hemos alcanzado la piedra angular". Estas metáforas también se refieren a la noción alemana "Weltbild" (OC $\S 94, \S 162)$. Todos nuestros juegos de lenguaje, todas nuestras acciones y pensamientos están basados en este fondo (OC § 253, § 492, § 97, § 162, § 248, § 211, § $94, \S 151, \S 96, \S 144, \S 655, \S 403, \S 103)$. La certeza objetiva en cuanto actitud doxástica se refiere a la manifestación no proposicional y se muestra, de acuerdo a la lectura de Moyal-Sharrock $(2005,2007)$, como un tipo de confianza ciega en lo que hacemos y revelamos al decir y al actuar; su objeto es parte de la gramática (OC $\S 153$ ), como cuando son objetos de experiencia (OC § 337): "Aquí hay una mano". Estas proposiciones funcionan como actitudes, tal como las reacciones.

Respecto de las "certidumbres objetivas", Moyal-Sharrock afirma que son los componentes específicos de las redes fundacionales y, por ello, se mantienen unidas (tal como señala Wittgenstein en OC $\S 279, \S 234, \S 141)$. Pero la asimilación de ellas, y esta es la aportación de Moyal-Sharrock, no es ni proposicional, ni empírica, ni epistémica. Las certidumbres objetivas son... subjetivas, pero subjetivas en el sentido de que son indesmentibles tanto para mí como para cualquier otro individuo. A partir de estas distinciones, la autora abona a favor de la interpretación fundacionista establecida por Stroll quien ya había distinguido también entre certeza subjetiva y certeza objetiva aunque con diferentes matices. En la explicación de las certidumbres objetivas, Moyal-Sharrok (2005, p. 83-84) señala que nuestra imagen del mundo puede ser divida en certezas individuales. Aunque matiza que están entretejidas en una red coherente de creencias, sin embargo enfatiza que su objetividad no es una certeza trascendente e insiste en que lo que se mantiene firme se mantiene firme para alguien. Desarrolla este aspecto unas páginas después (MoyalSharrok 2005: 94-96) y sostiene que las certidumbres objetivas cuentan para cada sujeto como sólidas, inmóviles e inquebrantables. Ciertamente, de nuevo matiza que su ocurrencia no es nunca meramente personal, sino, usando terminología de Stroll interpersonal (1994, p. 153). Mi preocupación con esta manera de leer nuestras certezas es que puede conducir a una concepción de ellas como algo -en este caso una actitud- entre el mundo y el sujeto. Este intermediario es a lo que consideraríamos fundamento del conocimiento. En este argumento, no estaríamos ante una evidencia de carácter perceptual ni una intuición inmediata sino ante una acti- 
tud instintiva o adquirida, algo que se hace. Pese a no ser proposicional, esta actitud seguiría fungiendo como un intermediario con carácter normativo. Y éste es justo el modelo que nos deja impotentes ante el ataque del escéptico. Recordemos que el escéptico es alguien que cuestiona la pertinencia de las razones que tenemos para sostener nuestras creencias. ¿En qué sentido estás actitudes funcionarían como una razón última para sostener nuestras creencias?, ¿no estarían también sujetas al cuestionamiento del escéptico? Es verdad que en lugar de ofrecer razones al escéptico, estaríamos ofreciéndole actitudes pero haciendo que jueguen el papel de razones. El escéptico podría nuevamente insistir en su duda. ¿Por qué una actitud es una respuesta adecuada a la pregunta acerca de la justificación del conocimiento? Según mi lectura, se está tratando a las certidumbres objetivas como en el modelo cartesiano se trató a las evidencias. No creo que ésta sea la estrategia adecuada para enfrentar al escéptico ni tampoco creo que sea la que adoptó Wittgenstein en $O n$ Certainty. No es eligiendo un nueva razón, una razón de distinto carácter, una actitud, como podemos parar la duda insaciable del escéptico.

7. No estoy de acuerdo con esta lectura, Wittgenstein no es fundacionalista. A continuación veremos por qué. En primer lugar, centraré mi respuesta en distanciarme del rol que tanto Moyal-Sharrock como Stroll hacen jugar a las proposiciones bisagra. Finalmente, apelaré al espíritu de la obra de Wittgenstein, a su carácter terapéutico, para enfrentar el supuesto fundacionismo wittgensteiniano.

Efectivamente, las criptoproposiciones o proposiciones bisagra enuncian creencias que no requieren justificación, pero si bien pueden ser esgrimidas como razones, su carácter no es el de base inamovible sino, más bien, el de nódulo temporal de significado. Y quiero enfatizar aquí tres rasgos distintivos de su condición, su condición de ser nódulo de significado. Estos son la temporalidad, la movilidad, la interdependencia y también la no-universalidad. Para enfatizar los dos primeros rasgos, recordemos el parágrafo 96 :

Podríamos imaginar que algunas proposiciones, que tienen la forma de proposiciones empíricas, se solidifican y funcionan como un canal para las proposiciones empíricas que no están solidificadas y fluyen; y también que esta relación cambia con el tiempo, de modo que las proposiciones que fluyen se solidifican y las sólidas se fluidifican (OC $\S 96)$.

Pero no sólo su temporalidad y la movilidad son importantes; es precioso destacar que el rol que juegan es dependiente del contexto lingüístico, -el juego de lenguaje-, y extralinguistico, -las formas de vida-. "Lo que se mantiene firme lo hace, no porque intrínsecamente sea obvio o convincente, sino porque se sostiene en lo que le rodea" (OC $\S 144)$. De manera que las proposiciones bisagra, incluso entendidas en su caracterización no proposicional, no son independientes. Su carácter de nódulo de significado, de bisagra, depende del rol que estén jugando y su 
aceptación se muestra en nuestras conductas (OC § 7, 204, 427-8, 284-5, 344). Las certezas expresadas en las criptoproposiciones adquieren su significado en tanto juegan un papel dentro de nuestras formas de vida (IP §19, 23, 241). De manera que, a diferencia de Stroll, no creo que podamos distinguir entre formas relativas y absolutas de certeza. Esta es una distinción engañosa que nos impide ver la relación existente entre las proposiciones bisagra y el resto de nuestro conocimiento. El siguiente parágrafo es bastante claro al respecto: "He llegado al fondo de mis convicciones. Y casi podría decirse que este fundamento es sostenido por el resto del edificio" (OC § 248). La certezas que Stroll llama absolutas, también dependen del resto del edificio; no son absolutas.

A diferencia de Moyal-Sharrock, considero que las proposiciones bisagra son extremadamente heterogéneas entre sí (OC §213) y no obedecen a ningún tipo de esencia o base común que pueda reconocerse como fundamento (Williams 2005). Más bien, constituyen una suerte de estructura que provee un entramado para el resto de nuestras creencias. El papel que juegan no es el de base sino el de estructura gracias a la cual podemos evaluar otras creencias. Se trata de una estructura de complejos apoyos que van cambiando. Una estructura que podemos imaginar como una red compuesta por nódulos. Los nódulos, las criptoproposiciones, nos permiten establecer redes de relaciones con otras creencias y con otros nódulos, otras criptoproposiciones. De manera que nada más lejos de la pirámide invertida de la que nos habla Stroll (1994, pp. 143-4). La noción de indubitabilidad que Wittgenstein promueve no es la clásica promovida por la epistemología tradicional. Y no puede, desde mi punto de vista, servirnos para defender un supuesto fundacionismo wittgensteiniano. Wittgenstein reclama una configuración del dar y pedir razones en la que las proposiciones bisagras o criptoproposiones son su marco de referencia y no su base; son esos nódulos que nos permiten establecer relaciones temporales y contextuales de normatividad epistémica. De modo que no se trata de pensar un sistema de creencias que se sostiene sobre la base de un conjunto de proposiciones indubitables, -recuerdo ahora la famosa metáfora sellarsiana de la tortuga sosteniendo un elefante-. Más bien, tenemos que entender que las criptoproposiciones no están exentas de evaluación epistémica por estar fuera de los juegos de lenguaje sosteniéndolos -como afirma Stroll-, sino que son ajenas a la lógica misma de la evaluación epistémica. Y no están sujetas a evaluación epistémica porque constituyen la estructura que permite la evaluación epistémica. En este sentido, tal como interpreto la propuesta wittgensteiniana, el pretendido, si tal hubiera sido el caso, "fundamento" del conocimiento, -esto es, las proposiciones indubitables-, no es una base sólida, independiente, inamovible y determinable $a$ priori (OC § 166). 9

\footnotetext{
9 Permítame señalar, a modo de paréntesis y abonando a la tesis interpretativa de la continuidad en las obra de Wittgenstein, que en el Tractatus también nos hablaba Wittgenstein de proposiciones, más bien
} 
Quedan aún por aclarar el rasgo de no-universalidad. Como señalé más arriba, las criptoproposiciones en que apoyamos nuestras creencias dependen del juego de lenguaje, están implícitas en nuestras prácticas. De manera que no están fuera, ni son un fundamento externo a nuestros juegos de lenguaje, como afirma Stroll. Las creencias que constituyen nuestro conocimiento, -todas ellas, las que se expresan en proposiciones bisagra y también las creencias que podemos poner en duda-, se encuentran vinculadas con las prácticas lingüísticas (juegos de lenguaje) y extralingüísticas (formas de vida) realizadas o dadas en contextos. Al mismo tiempo, dichos juegos de lenguaje y formas de vida son constituidos por estas creencias, por todas ellas (OC 141). Para establecer que una proposición es una criptoproposición requerimos un contexto, no puede establecerse a priori, ni de manera universal. El que podamos señalar una proposición como criptoproposición depende del juego de lenguaje que estemos jugando. De manera que, a diferencia de MoyalScharrok, considero que también éstas son temporales, móviles, interdependientes y contextuales; no pueden ser entendidas pues, como una base autónoma a la manera de fundamento.

Hasta aquí mi lectura discrepante de las proposiciones bisagra. Pero aún quiero añadir un argumento más a favor de mi rechazo a la lectura fundacionista de Wittgenstein. Apelaré ahora a lo que podríamos llamar el espíritu de su obra: su carácter terapéutico. Coincido con Pritchard (2011) en que para Wittgenstein el escéptico está totalmente divorciado del lenguaje ordinario. El conocimiento está vinculado a la posibilidad de dar razones. Recordemos lo que Wittgenstein señala con relación al conocimiento:

Uno dice "Yo sé" cuando uno está listo para dar razones irresistibles. "Yo sé" se refiere a una posibilidad de demostrar la verdad. [...] Pero si lo que él cree es de tal índole que los fundamentos que puede dar no son más seguros que el aserto, entonces él no puede decir que sabe lo que cree. (OC, §243)

pseudo-proposiciones, que juegan un papel demarcador: las proposiciones de la lógica (TLP 6.1). Son proposiciones que no pueden ser confirmadas ni falsadas por la experiencia. Ellas son las que determinan lo que puede ser dicho con sentido, los límites del significado, los límites del mundo. Análogamente, en On Certainty existen proposiciones, las criptoproposiciones, que establecen los límites de lo que puede ser dicho con sentido. La diferencia en este último caso es que este límite es temporal y se establece en relación con unas formas de vida y los juegos de lenguaje. Podemos así establecer cierta analogía entre la noción de gramática, -constituida por el conjunto de reglas y observaciones gramaticales que norman nuestro lenguaje-, y la lógica en la perspectiva del Tractatus. Así, la lógica determina los límites de nuestro lenguaje que son los límites del mundo. Aquello que está más allá de los límites de mi lenguaje no es inteligible, no lo puedo conocer. También la gramática, esto es el conjunto de reglas gramaticales, de criptoproposiciones, que norman el uso que hacemos de nuestro lenguaje, nos permite establecer los límites de lo que puede ser conocido, de lo que puede ser dicho con sentido. Aunque en este caso, como dije, las reglas gramaticales no determinan una idea de límite restrictiva, demarcadora; los límites no son fijados a priori, son, por el contrario, flexibles, arbitrarios. 
El ataque de Moore al escéptico, que Wittgenstein objeta en On Certainty, se construye sobre la base de una concepción errónea de la estructura de las razones, de cómo éstas se engranan. Cuando se sostiene "Aquí tengo una mano", qué razón podríamos esgrimir a favor. Las razones que podríamos ofrecer a favor de esta creencia no son más poderosas que la creencia misma, no podrían jugar un rol de justificación. Las proposiciones que enuncian este tipo de creencias, como hemos señalado más arriba, no requieren razones, ellas mismas constituyen el marco de referencia respecto al cual podemos dar razones. En términos de Strawson, las cripto-proposiciones pueden servir como razones para el resto proposiciones pero no requieren de justificación. Ahora bien, no olvidemos que estas proposiciones no pueden ser declaradas como conocidas, o dudadas, porque las criptoproposiciones, están fuera de la ruta epistémica. Es justo en este punto donde Wittgenstein está enfrentado a Moore.

La posibilidad de duda es cuestión epistémica, y la certeza que nos ofrecen las criptoproposiciones, aquélla en la que se enmarca el significado de nuestros juegos de lenguaje, no entra en el juego del escepticismo. Sólo los filósofos se han enredado en el planteamiento de la duda aquí. En nuestra vida cotidiana no cabe la duda de estas creencias, pues dudar de ellas, en una comunidad de habla concreta, significaría que nos declaren desadaptados o locos. Estas son creencias que aceptamos al ser introducidos en una forma de vida, en sentido estricto no tenemos conocimiento de ellas.

Wittgenstein en On Certainty nos presenta una descripción de cómo funcionan nuestros sistemas de creencias. No encuentro en el análisis del texto presentado hasta aquí ningún anhelo de construir una teoría del conocimiento que contraponer al escéptico sino una descripción que tiene un afán terapéutico y no teórico. Esta actitud de Wittgenstein se pone de manifiesto en el tratamiento de la respuesta de Moore al escéptico. Moore sostiene una pretensión de saber allí donde no puede haber un desafío relevante (¿Alguien duda de que tenemos manos?). Para Pritchard (2011), esta posición de Wittgenstein se observa con claridad en On Certainty (OC§ 125). Wittgenstein quiere erradicar el hábito de abusar de la concepción de duda, de las expresiones de duda, erradicar la idea de que ellas son "libres", ya que, en realidad, no pueden entrar en el juego de dar un pedir razones sin una motivación, de otra forma son incoherentes (OC $\S 122-123$ ).

Ludwig Wittgenstein, en On Certainty, distingue entre lo que es vano someter a objeto de razonamiento, lo que debemos dar por sentado en todos nuestros razonamientos y lo que genuinamente es objeto de cuestionamiento. Su actitud frente al escéptico es precisamente rechazar la duda escéptica profesional, la de los filósofos. $\mathrm{Su}$ estrategia no consiste en rebatirla sirviéndose de un argumento, como trata de hacer Stroll con su interpretación, sino señalar que es inútil, irreal y engañosa; dicho de otro modo, se trata de motrar que es vano someterla a razonamiento alguno. 


\section{Naturalismo y quietismo}

1. Una tema tengo aún pendiente, dada la caracterización de naturalismo que aplico a esta propuesta, ¿de qué manera diría el segundo Wittgenstein que establecemos el valor de verdad de una determinada creencia no exenta de duda, es decir, una pretensión cognoscitiva cualquiera? ¿No será en función de las evidencias que aportan nuestras experiencias? 10 Comenzaré mi respuesta señalando que Wittgenstein no se detiene a discutir la tesis de la independencia de mundo extralingüístico respecto del lenguaje. Dicha independencia se pone de manifiesto en la relevancia que otorga a las prácticas lingüísticas en contextos extralingüísticos para poder pensar el significado de los términos -en las Philosophical Investigations ${ }^{-}$; y para aceptar o rechazar ciertas creencias como verdaderas o no, incluso para determinar si una creencia es un sinsentido propio de un demente o un error comprensible, -en On Certainty-. Paralelamente Wittgenstein vincula la actividad humana a los rasgos de la realidad. De modo que los vínculos entre mundo y lenguaje se presentan en una relación de mutua dependencia. Con sus propias palabras:

No digo: Si tales y cuales hechos naturales fueran distintos, los seres humanos tendríamos otros conceptos (en el sentido de una hipótesis) Sino: Quien crea que ciertos conceptos son los correctos sin más; que quien tuviera otros, no apreciaría justamente algo que nosotros apreciamos - que se imagine que ciertos hechos naturales muy generales ocurren de manera distinta a como estamos acostumbrados, y le serán comprensibles formulaciones conceptúales distintas a las usuales (IF II, XII).

Efectivamente, Wittgenstein distingue entre razones que permiten justificar una creencia y causas de una creencia. Al aprender un lenguaje asumimos prácticas sociales, dichas prácticas suponen formas compartidas de proceder culturalmente transmitidas. Estas nos servirán, cuando se requiera, como razones para justificar nuestras creencias.

La pregunta acerca del papel que juega la experiencia en la justificación de nuestras creencias acerca del mundo pone de manifiesto una preocupación por lo que Brandom denomina la 'dimensión representadora' (Brandom: 1994). Wittgenstein, como es sabido, rechaza que el fundamento de nuestro conocimiento del mundo esté basado en la representación que de él nos hacemos, en las proposiciones con las cuales lo retratamos, apela en cambio a nuestro tráfico con él. Sus observaciones acerca del lenguaje ponen de manifiesto que lo conceptual se articula socialmente. La pregunta acerca de la posibilidad o imposibilidad de justificar nuestras creencias acerca del mundo descansa, en último término, en una cuestión gramatical, normativa. Por ello, requiere, dado su carácter, explicitar la noción

10 Debo y agradezco a un(a) lector(a) anónimo(a) este cuestionamiento. 
misma de lenguaje como praxis socialmente compartida. Requiere, en el contexto semántico, mostrar que la justificación filosófica del uso de una expresión lingüística es el uso o aplicación de la misma en circunstancias concretas. En el contexto epistémico, la justificación de nuestras creencias tiene su soporte en el marco de referencia, en la estructura de nódulos que está constituida por el entramado de criptoproposiciones. El peso normativo de esta propuesta recae en la coincidencia de los significados compartidos, o lo que es lo mismo, la coincidencia en una comunidad de creencias. Entender un lenguaje nos remite a un "saber actuar", estando, empero, esa acción lingüística ligada a expectativas de comportamiento socialmente asumidas: lenguaje y acción son momentos del mismo modelo que es el juego del lenguaje. Toda práctica lingüística implica, entonces, la aplicación de reglas que nos permiten determinar ese "saber actuar". Es importante insistir en que la normatividad wittgensteiniana no se ocupa, en sentido estricto, de la relación de un nombre con un objeto, o de una proposición con un hecho del mundo sino de la relación entre proposiciones y creencias con prácticas sociales. La gramática establece el lugar de un concepto en nuestro sistema de conceptos y, por tanto, en nuestro mundo (IF 257). La gramática, la normatividad que rige nuestro lenguaje, no es una teoría acerca de la realidad, sino el cauce que permite articular diversas teorías sobre la realidad. En este sentido, la preocupación gramatical no es una pregunta por los fenómenos sino por la posibilidad de conocer y hablar acerca de los fenómenos.

El lenguaje se aprende a partir de los distintos contextos de uso de una expresión, de manera que la expresión es articulada no sólo al interior del lenguaje sino también en el contexto extralingüístico de uso de la expresión. Si el contexto extralingüístico de uso, el mundo, fuera distinto, distinta sería también la gramática. Recurramos a un ejemplo wittgensteiniano:

Imaginemos este caso: las superficies de las cosas de nuestro entorno (piedras, planta, etc.) tienen manchas y zonas que ocasionan dolor a nuestra piel al tocarlas. (Quizás por la composición química de estas superficies. Pero no necesitamos saberlo) entonces, así como ahora hablamos de una hoja de una determinada planta con manchas rojas, hablaríamos de una hoja con manchas dolorosas. (...) (IF 312)

Con este ejemplo se nos muestra cómo es posible establecer la relación entre la gramática y nuestro mundo. Aquélla limita nuestro acceso al mundo, empero, su carácter normativo no puede ser entendido como un límite a los fenómenos que pueden darse o no en el mundo, lo que sí limita son las posibilidades conceptuales de lo que podemos descubrir en nuestro mundo. El límite de lo empírico es la formación de conceptos. Ahora bien, nuestros conceptos no son el vehículo de ideas que tenemos en la mente ni la etiqueta del objeto que señalamos. Recordemos que "[e]s nuestra actuación lo que yace en el fondo del juego de lenguaje" (OC 204). 
En esta propuesta la justificación es cuestión de práctica social e interacción en un mundo compartido. Lo que no sea práctica social no ayuda a entender la justificación del conocimiento humano, independientemente de que pueda servir para aclarar cuestiones acerca de su adquisición. No es posible otra cosa que no sea constatar la concordancia de los hombres en sus prácticas lingüísticas (IP 241). Dichas prácticas descansan en nuestras formas de vida, las formas de vida humana. Strawson ha calificado esta concepción de naturalismo suave: aquella perspectiva filosófica que se limita a señalar una serie de creencias como sedimentadas en nuestra naturaleza humana de tal manera que podríamos caracterizarlas como "pre-epistémicas", es decir, no pueden convertirse en tema de investigación y, por lo tanto, están "exentas de duda"; ellas constituyen el andamiaje de todo nuestro pensamiento (Strawson 1999, pp. 135-160). Wittgenstein no habla de la Naturaleza Humana, sino de nuestro aprendizaje desde la niñez, de una actividad, de una práctica social. Un aprendizaje no intelectivo sino adiestramiento en una práctica. Las criptoproposiciones, las proposiciones exentas de duda, no son juicios aprendidos intelectualmente; son la expresión de prácticas sociales en las que somos adiestrados al ser introducidos en una forma de vida. En ello radica el carácter social de esta forma de naturalismo.

2. A diferencia de Brian Leiter, quien -en una compilación de 2004 titulada The future for Philosophy-distingue entre dos tribus filosóficas anglosajonas contemporáneas: los quietistas wittgensteinianos y los naturalistas, prefiero recurrir a los planteamientos de Michael Williams (1996, XVII). Este último distingue, a la hora de afrontar el reto escéptico, entre una actitud de diagnóstico frente al escepticismo de corte terapéutico o bien teórico.

McDowell puede ubicarse entre los filósofos que tras el diagnóstico se propone atender, como proyecto de investigación, las distintas ideas acerca de justificación y conocimiento. De manera que como buen diagnosticador teórico se propone redistribuir los límites de la teoría. Wittgenstein por el contrario, no nos ofrece una nueva teoría sino como una práctica consistente en mostrar los usos de nuestros conceptos con el fin de llevar a cabo, en su caso, una terapia. Wittgenstein, al negarse a contestar las objeciones del escéptico, pone de manifiesto un diagnóstico, a saber: las objeciones escépticas acerca del conocimiento y acerca del significado (algo diré de ésta un párrafo más abajo) vienen ya prefiguradas por un modo de preguntar típico de filósofos. Un modo de preguntar que implica la demanda de una teoría general acerca del conocimiento y con relación al significado de las palabras. Esta forma de preguntar carece de sentido por generar falsos problemas. Wittgenstein no ofrece una teoría alternativa sino un nuevo modo de preguntar. Un cuestionar que no tiene como horizonte la búsqueda de teorías generales alternativas a las ya existentes (IP $\S 109, \S 118, \S 119, \S 128, \S 133$ ), sino el cuidado y el rigor que supone atender al caso particular y a las circunstancias concretas. Ofrece, un nuevo modo de ver 
(Anschauungsweise, IP §144) que nos permite diagnosticar un falso problema filosófico. En este sentido, podríamos concluir que la tarea de la filosofía desde una perspectiva wittgensteiniana es eminentemente crítica, digamos, deconstructiva (Stone 2000).

[La investigación filosófica, -nos dice Wittgenstein-] nace no de un interés por los hechos del acontecer natural, ni de la necesidad de captar conexiones causales. Sino de una aspiración a entender el fundamento, o esencia, de todo lo que la experiencia enseña. Pero no como si debiéramos para ello rastrear nuevos hechos: es más bien esencial a nuestra investigación el que no queramos aprender nada nuevo con ella. Queremos entender algo que ya está patente ante nuestros ojos. Pues es esto lo que, en algún sentido, parecemos no entender. (IF § 89)

3. Un ejemplo que nos permite ilustrar la idea de terapia como diagnóstico, o de diagnóstico terapéutico, lo encontramos en tratamiento que da Wittgenstein a la llamada paradoja presentada en el parágrafo 201 de las Investigaciones Filosóficas. ${ }^{11}$

Nuestra paradoja era ésta: una regla no podría determinar ningún curso de acción porque todo curso de acción puede hacerse concordar con la regla...

Y en el mismo parágrafo, tras enunciar la paradoja, señala:

Que hay ahí un malentendido se muestra en que en este curso de pensamientos damos interpretación tras interpretación [...] Con ello mostramos que hay una captación de una regla que no es una interpretación, sino que se manifiesta, de caso en caso de la aplicación, en lo que llamamos "seguir la regla" y en lo que llamamos "contravenirla".

En el contexto de la paradoja, lo que se está poniendo en cuestión son los vínculos entre significado y normatividad, o en otros términos, la relación que debe establecerse entre la comprensión de un signo y el seguimiento de reglas (la acción que debe llevar a cabo siguiendo la regla lingüística que implica el signo). Si no es posible establecer dichos vínculos, se anula el lenguaje, todo lenguaje posible. Saul Kripke (1982) atribuye a Wittgenstein la aceptación del reto planteado por la paradoja y encuentra en las Investigaciones Filosóficas un 'solución escéptica'. De acuerdo con Kripke, el que Wittgenstein afirme que no disponemos de ningún un hecho ni estado mental para justificar el seguimiento de reglas, o en otras palabras, el uso de términos, supone aceptar el desafío escéptico, al que se da respuesta aten-

\footnotetext{
11 Kripke, en su interpretación del parágrafo 201, sostiene literalmente que "él (Wittgenstein) acepta su propio argumento escéptico y ofrece una 'solución escéptica' para superar la apariencia de paradoja.” (Kripke 1982) (Para la cita Kripke 1989, p. 71). He discutido esta interpretación en (Muñoz, Mayo 2007, 58 (II), pp. 77-93).
} 
diendo a las condiciones de asertabilidad y a la función que el lenguaje juega en las formas de vida. Esta respuesta es considerada por él como una solución escéptica 12.

Mi lectura, a diferencia de la kripkeana, es que Wittgenstein no propone una nueva teoría, digamos una nueva versión del escepticismo, en este caso el escepticismo semántico, ni tampoco propone darle una "solución escéptica" a la paradoja sino disolver malentendido, un enigma equívoco, mostrando los hilos del argumento. Wittgenstein formula tal paradoja para disolverla, para mostrar que es un falso problema surgido de una mala concepción de la atribución de significado a los términos y del vínculo que se debe establecer entre significado y normatividad. Una lección del manejo wittgensteiniano de la paradoja es la necesidad de un diagnóstico de por qué tenemos la inclinación a caer en supuestos peculiares que convierte a tales "paradojas" en problemas urgentes. Dado un diagnóstico satisfactorio, la inclinación debería evaporarse, y también las falsas paradojas ${ }^{13}$.

La elaboración de un diagnóstico nos ofrece sí, una forma de conocimiento, si bien no una tesis sustantiva que resuelva nuestro problema filosófico. Esta interpretación de la propuesta terapéutica es, sin embargo, débil, puesto que no implica un precepto de silencio filosófico, un quietismo en el sentido estricto. Se trata, más bien, de quitarle dramatismo a las afirmaciones quietistas y enfatizar la importancia de la filosofía como diagnóstico terapéutico.

\section{Conclusión}

1. La problemática que nos ocupaba desde el inicio de este texto, -la relación entre conocimiento y normatividad o justificación epistémica- ha sido atendida sin sucumbir al escepticismo. Tampoco hemos necesitado apelar a la experiencia como tribunal desde el cual evaluar nuestras creencias. El valor de verdad de muchas de

12 Entre otros, Baker and Hacker (1984) señalan que el escepticismo es una lectura insensata de Wittgenstein. Lo que Wittgenstein estaría negando es que se tenga que justificar el significado apelando a rasgos de la realidad o de la mente, sin que ello, suponga caer en el escepticismo. Para ellos, Wittgenstein sostiene que no hay nada que pre-exista a la aplicación de un concepto que sea universal o universalizable.

$13 \mathrm{McDowell}$, en su texto acerca de seguir una regla también quita peso al llamado quietismo wittgensteiniano, en oposición a la lectura de Crispin Wright (McDowell 1998, pp. 211-262). En "Significado e Intencionalidad en la fillosofía del último Wittgenstein", McDowell sostiene que no sería característico de Wittgenstein dejar sin cuestionar tesis y avocarse a un quietismo que evitara enfrentar los problemas que destapa - problemas tales como ‘¿Cómo es posible el significado?’ “¿Cómo es posible la intensionalidad?' Según McDowell, una lección del manejo wittgensteiniano del argumento del regreso de las interpretaciones es la necesidad de un diagnóstico de por qué tenemos la inclinación a caer en un supuesto peculiar que convierte a tales preguntas en problemas urgentes. Dado un diagnóstico satisfactorio, la inclinación debería evaporarse, y las preguntas simplemente deberían caer por su propio peso. (McDowell 1988, p. 273). 
nuestras creencias no corresponde a la corroboración de hechos empíricos, sino que depende de la confianza en y la aceptación de un conjunto de creencias compartidas por la comunidad de hablantes a la que pertenecemos. Sólo en el marco de contextos lingüísticos podemos apelar a una cierta noción de objetividad del conocimiento, sin por ello asumir presupuestos realistas ni escépticos. Y ésta, más que una respuesta, es una disolución de una aparente paradoja: Ni renuncia al conocimiento como nos pide el escéptico ni recurso a la experiencia tal como se propone en el empirismo mínimo.

La propuesta de McDowell supone un modelo de normatividad para el conocimiento que prescinde del contexto, de las condiciones histórico-sociales de producción del conocimiento y de articulación de significado. Tal modelo de normatividad es el que he confrontado con la noción de normatividad implícita en la propuesta wittgensteiniana. En esta interpretación, he mostrado una idea de la normatividad que nos abre a la posibilidad de descentrar el mundo y desmitificar la razón.

He argumentado de la mano de Wittgenstein que la relación entre el lenguaje y el mundo es de carácter normativo en un doble sentido: por un lado, se considera como un supuesto irrenunciable para que nuestros conceptos sean significativos que existe un mundo en el cual nuestras prácticas son significativas; y por otro lado, ese mundo, que funciona como un constreñimiento para el uso de nuestros conceptos, depende de nuestras creencias y juicios. Usando, ahora sí, las palabras de McDowell, "no hay una fisura ontológica entre el tipo de cosas que uno puede querer decir -o, en general, el tipo de cosas que uno puede pensar- y el tipo de cosas que pueden ser el caso". Ahora bien, este constreñimiento que propongo, a diferencia de McDowell, se apoya en el carácter social del lenguaje. ${ }^{14}$ Así, para responder a la inquietud relativa a la relación entre la mente y el mundo, o para decirlo correctamente, entre nosotros y el mundo, no necesitamos apelar a un dato conceptualmente puro, ni a una experiencia conceptualmente mediada, sino partir de nuestras prácticas socialmente compartidas y gramaticalmente estructuradas, de forma que evitamos tanto la caída en el Mito de lo Dado como en el Mito de la Construcción ${ }^{15}$ o coherentismo. Lo que podemos objetar, siguiendo a Wittgenstein, no es que las afirmaciones de coherentistas o verificacionistas sobre la justificación del conocimiento sean incorrectas, sino que desvinculan ésta del contexto público y semántico en

14 De manera que se encuentra más próximo a la concepción de responsabilidad hacia los otros que propone Brandom en Making It Explicit. En esta obra, Robert Brandom señala que las inferencias son los mecanismos para la transmisión de justificación; sin embargo, también reconoce que la justificación puede ser transmitida por comunicación deferencial, es decir, por el testimonio de otra persona. Brandom concibe la normatividad no como "responsabilidad hacia el mundo", sino como responsabilidad de los seres humanos los unos hacia los otros. En el modelo de Brandom, toda fuente de justificación es social (Brandom 1994).

15 Vid., Carlos Pereda, ¿Qué es el mundo?, versión en fotostáticas. 
el que se originan, olvidando, así, que la noción de justificación de las creencias está estrechamente unida con las prácticas sociales de las comunidades de certezas.

2. La concepción wittgensteiniana del lenguaje constituye una forma de naturalismo consistente en la afirmación del postulado pragmático que subraya la importancia central de los lenguajes naturales en la definición y organización de nuestras prácticas y nuestra experiencia del mundo. La evidencia de que no disponemos de un lenguaje supremo que nos permita una descripción definitiva de la realidad, no entraña que esta última no exista o esté perdida para nuestro conocimiento, sino, simplemente, que cualquier cosa que digamos acerca de ella conlleva un juicio que debe apoyarse en creencias compartidas.

En On Certainty, Wittgenstein nos ofrece una descripción de nuestro lenguaje que enfatiza el papel de las proposiciones indubitables, las criptoproposiciones o proposiciones bisagra como creencias compartidas que constituyen el marco de referencia. Estas vienen a constituir la gramática de nuestro lenguaje. Sin embargo, a diferencia de las pseudoproposiones de la lógica en el Tractatus, las criptoproposiciones no pueden establecerse a priori, no son ni independientes, ni atemporales ni inmóviles ni universales (Vid. Williams 2005, p. 51). Por esto mismo no podemos hacer una lectura fundacionista de esta última obra de Wittgenstein. Para Wittgenstein, el contenido de las creencias básicas de los seres humanos acerca del mundo no está formado por representaciones mentales privadas, sino por situaciones y eventos comunes e intersubjetivos que dependen de formas de vida dadas. Leer las proposiciones indubitables wittgensteinianas como certidumbres básicas objetivas a la manera de Moyal-Schrook, o como certezas objetivas o subjetivas a la manera de Stroll, abre la puerta al modelo cartesiano de justificación del conocimiento. De nuevo, caemos en la tentación de ubicar entre el mundo y nuestro conocimiento entidades intermedias a las que adjudicamos el papel de fundamento. No hay tal. El papel central de las creencias básicas en el conjunto de la vida mental, de acuerdo con la concepción representativa de la mente de raíz cartesiana, no es correcto: no hay representaciones mentales intermedias entre el sujeto y el mundo. Del mismo modo, para dar cuenta del conjunto de nuestras creencias, así como de la validez de nuestro conocimiento tampoco requerimos de intermediarios -ni experiencia conceptualmente mediada ni certidumbres objetivas - a los que adjudicamos el rol de fundamento.

Los planteamientos de Moyal-Schrook y Stroll tanto como la propuesta de McDowell son fruto de una ansiedad filosófica: el deseo insaciable de resolver enigmas equívocos. Los tres buscan construir una nueva teoría del conocimiento donde lo que se requiere es un buen diagnóstico. 


\section{Referencias bibliográficas}

BAKer, G., y HACKer, P.M.S. (1984): Skepticism, rules and language, Oxford, Blackwell.

BLoor, D. (1983): Wittgenstein: A Social Theory of Knowledge, New York, Columbia University Press.

Brandom, R. (1995a): "Perception and Rational Constraint: McDowell's Mind and World", Philosophical Issues, 7.

Brandom, R. (1995b): "Knowledge and the Social Articulation of the Space of Reasons", Philosophy and Phenomenological Research, LV, ${ }^{\circ} 4$.

Brandom, R. (1994): Making It Explicit. Reasoning, Representing, and Discursive Commitment, Cambridge Mass., Harvard University Press.

Byrne, A. (2005): "Perception and Perceptual Content", en M. Steup, \& E. Sosa (edits.), Contemporary Debates in Epistemology Malden, Estados Unidos de América: Blackwell Publishing: 231-250.

CARdona, C.A. (2011): “¿Es Wittgenstein un fundacionalista?”, Ideas y valores, Vol. LX, núm. 146, 73-95.

DAVIDSON, D. (1983): "A Coherence Theory of Truth and Knowledge", en Subjective, Intersubjective, Objective Oxford, Clarendon Press: 137-153

De Caro, M. y Macarthur, D. (comps) (2004): Naturalism in question, Harvard University Press, Cambridge, Mass.

De VRies, W. A., \& Triplett, T. (2000): Knowledge, Mind and the Given: Reading Wilfrid Sellars's "Empiricism and the Philosophy of Mind", Indianapolis, Estados Unidos de América: Hackett.

HaAcK, S. (2009): Evidence and Inquiry: A Pragmatist Reconstruction of Epistemology (2da ed.). Amherst, Estados Unidos de América: Prometheus Books.

Kenny, A (1984): "Wittgenstein on the Nature of Philosophy", en A Kenny, The Legacy of Wittgenstein, Oxford, Basil Blackwell

KrIPKE, S. (1982): Wittgenstein on Rules and Private Language, Harvard University Press

LeITER, B. (comp) (2004): The future for Philosophy, Oxford, Clarendon Press

Malcom, N. (1986): Nothing is hidden. Wittgenstein's Criticism of Early Thought, Oxford, Basil Blackwell.

Mcdowell, J. (2008): "Naturalism in the Philosophy of Mind" in Mario De Caro and David Macarthur (comps.), Naturalism in question, Harvard University Press, Cambridge, Mass.

MCDowell, J. (1998a): "Meaning and Intentionality in Wittgenstein's Later Philosophy", en Mind, Value and Reality, Cambridge, Harvard University Press, 263-278 
Mcdowell, J. (1998b): "Wittgenstein on Following a Rule", en Mind, Value and Reality, Cambridge, Harvard University Press, 221-262.

Mcdowell, J. (1994): Mind and World. Cambridge: Harvard University Press. MedinA, J. (2004) “Wittgenstein's Social Naturalism: The Idea of 'Second Nature' After The Philosophical Investigations" en Danièle Moyal-Sharrock (Ed.), The Third Wittgenstein: The Post-Investigations Works, Ashgate, England.

Moyal-Sharrock, D. (2004a): Understanding Wittgenstein's On Certainty. London: Palgrave.

Moyal-Sharrock, D. (2004b): "Introduction: The idea of a third Wittgenstein", en D. Moyal-Sharrock (edit.), The Third Wittgenstein: the Post-Investigations Works. Aldershot: Ashgate, 1-12.

Moyal-Sharrock, D. (2005): "Unraveling Certainty" en D. Moyal-Sharrock y W. Brenner (edits.), Readings of Wittgenstein's On Certainty. London: Palgrave, 76-100.

MuÑoz, M., (2007): "La posibilidad de dar razones. Un acercamiento a la paradoja wittgensteiniana", Dianoia, 58 (II): 77-93.

PritchARD, D. (2007): "Wittgenstein's On Certainty and Contemporary Anti-skepticism", en D. Moyal-Sharrock y W. Brenner (edits.), Readings of Wittgenstein's On Certainty. London: Palgrave, 189-224.

Pritchard, D. (2011): "Wittgenstein on Scepticism”, en M. McGinn (edit.), Oxford Handbook to Wittgenstein. New York: Oxford University Press.

RheEs, R. (2003): Wittgenstein's On Certainty. There- Like Our Life. Oxford: Blackwell.

Roessler, J. (Oct. de 2009): "Perceptual Experience and Perceptual Knowledge", Mind, 118 (472), 1013-1041.

Rojas PARADA, J.L., (2009): "Experiencia y Juicio. De Davidson a McDowell y más allá”, Convivium 22: 171-194.

RORTY, R. (2000): "La idea misma de una responsabilidad humana hacia el mundo: la versión del empirismo de John McDowell" en Verdad y progreso. Escritos filosóficos 3, Barcelona, Paidós.

RORTY, R. (1993): "Wittgenstein, Heidegger y la reificación del lenguaje" Ensayos sobre Heidegger y otros pensadores contemporáneos, Barcelona, Paidós.

SEllars, W. (1997): Empiricism and The Philosophy of Mind, Cambridge, Massachusetts, Harvard University Press,

Stone, M. (2000): "Wittgenstein on deconstruction", en Alice Crary y Rupert Read (edits.), The new Wittgenstein, Londond and New York, Routledge.

STRAWSON, P., (1999): Escepticismo, naturalismo y argumentos trascendentales, en I. Cabrera (comp.), Argumentos Trascendentales, México, UNAM-Instituto de Investigaciones Filosóficas.

Stroll, A. (1994): Moore and Wittgenstein on Certainty. Oxford: Oxford University Press. 
Stroll, A. (2004): “Wittgenstein's Fundational Metaphors" en D. Moyal-Sharrock (edit.), The Third Wittgenstein: the Post-Investigations Works. Aldershot: Ashgate: 13-24.

Stroll, A. (2005): "Why On Certainty matters", en D. Moyal-Sharrock y W. Brenner (edits.), Readings of Wittgenstein's On Certainty. London: Palgrave, 33-46.

TANG, R. (Jul. de 2010): "Conceptualism and the New Myth of the Given", Synthese, 175(1), 101-122.

VAhid, H. (2008): "Experience and the Space of Reasons: The Problem of Nondoxastic Justification", Erkenntnis, 69 (3), 295-313.

VillarmeA, S. (2010): "Another turn of the screw: scepticism and propositional analysis", Wittgenstein-Studien, Internationales Jahrbuch für WittgensteinForschung, 1: 221-242,

Williams, M. (1996): Unnatural Doubt. Epistemological Realim and the Basis of Scepticism, Princeton University Press, Princeton.

Williams, M. (2005): “Why Wittgenstein Isn't a Foundationalist", en D. MoyalSharrock y W. Brenner (edits.), Readings of Wittgenstein's On Certainty. London: Palgrave, 47-58.

Wittgenstein, L. (1991): On Certainty. Oxford, Blackwell.

WitTgenstein, L. (1989): Sobre la certeza, Barcelona, Gedisa.

WitTGensteIn, L. (1988): Investigaciones filosóficas, UNAM, Crítica, Barcelona.

Wittgenstein, L. (1985): Philosophical Investigations, (ed. G.E. M. Anscombe and R. Rhees), Oxford, Blackwell.

María Teresa Muñoz Sánchez

División de programas directivos y posgrado

Universidad Intercontinental

mmunoz@uic.edu.mx 